\title{
ROUPAS PARA MAMÃES: CORPO E GRAVIDEZ NAS REPRESENTAÇÕES PARA A MATERNIDADE NA REVISTA MANEQUIM (1963)
}

\author{
Maternity clothes: body and pregnancy in \\ representations for maternity in Manequin Magazine \\ (1963)
}

\section{Ivana Guilheme Simili ${ }^{*}$}

\begin{abstract}
RESUMO
Examinar as representações para a maternidade por meio da análise das roupas para grávidas que circularam na revista Manequim, notadamente, na edição especial "Futura mamãe", de 1963, é o objetivo deste texto. Nossa abordagem discute como a gestação é incorporada pela moda e como esta produziu e difundiu representações para o corpo grávido. No artigo, indicamos, ainda, como as transformações corporais definiram linhas de indumentárias apropriadas à gestação nos anos 1960 e como estas assimilaram tendências e estilos da moda jovem, o que contribuiu para a ampliação do consumo.
\end{abstract}

Palavras-chave: Roupas; Moda; Maternidade

\begin{abstract}
To examine the representations for motherhood through the analysis of the pregnancy clothes that circulated in the Manequim Magazine, especially in the special edition "future mommy", of 1963 , is the purpose of this text. Our approach discusses how gestation is incorporated by fashion and how it produced and disseminated representations for the pregnant body with the values of motherhood. In the article, we show how corporal transformations defined clothing lines appropriate to gestation in
\end{abstract}

\footnotetext{
* Professora da Universidade Estadual de Maringá.
} 
the 1960's, assimilating influences of trends and styles of young fashion, factors that contributed to the expansion of the consumption.

Keywords: Clothes; Fashion; Maternity

\section{Introdução}

Foi nos anos 1960 que a maternidade ganhou evidência na moda brasileira. No bojo das transformações ocorridas no período, decorrentes da ampliação do mercado de roupas e de informações sobre moda, que absorvem os aspectos geracionais e de gênero como instrumentos para o consumo, é que, em meio às distinções entre corpos e indumentárias para jovens e senhoras, a gravidez é vestida pela moda.

A publicação pela revista Manequim, em 1963, do suplemento especial dedicado à "Futura Mamãe", foi considerada como índice das mudanças no tratamento dispensado pela moda à gravidez e à maternidade. Criada em 1959, pela editora Abril de Victor Civita, a revista atuou como um dos veículos para a promoção da moda nacional e de estímulo ao consumo dos bens e produtos por ela oferecidos. Foi o primeiro periódico a tratar exclusivamente de moda com as mulheres que, então, passaram a acompanhar as tendências mensalmente, nos modelos e moldes oferecidos, apropriando-se das ideias, sugestões e orientações, reproduzindo-as ou empregando-as como inspirações para os usos pessoais.

Nas edições da Manequim como registros históricos das experiências sociais e culturais vivenciadas pelas mulheres, nos seus relacionamentos com os corpos, as roupas e a moda, as transformações corporais e as criações de sentidos para as etapas da vida, da juventude à velhice, foram cruzadas de diferentes modos e por meio de várias estratégias de comunicação visual.

Em 1963, a edição para a Futura Mamãe marcou o momento em que uma temática do corpo feminino e sobre o qual havia silêncios e tabus, a gestação, ganhou visibilidade na imprensa. Ao 
assimilar o assunto em sua linha editorial, a Manequim instrumentalizava as roupas para produzir e disseminar representações para um corpo em transformação, vestindo-o com os valores da maternidade.

As representações, como pensadas nesse texto, tem o suporte na definição de Jodelet como "forma de conhecimento socialmente elaborada e compartilhada, que tem um objetivo prático e concorre para a construção de uma realidade comum a um conjunto social". ${ }^{1}$ Nas representações de corpo grávido, construídas por meio das propostas indumentárias dos modelos apresentados e das estratégias de consumo empregadas na edição da Manequim, as mulheres assimilavam os significados dos valores sociais e culturais da maternidade.

\section{Histórias das roupas e do vestir das grávidas}

Desde o surgimento da moda feminina, como prática de vestir os corpos, a linguagem não verbal das roupas transformou-se em recurso estético e simbólico para representar a maternidade e levar as mulheres a perceberem os papéis de gênero ${ }^{2}$ relativos à gestação e aos processos envolvidos no tornar-se mãe.

A valorização do peito e do ventre que está na origem da estruturação do traje feminino entre os séculos XIV e XV, ajudam a entender não somente o surgimento da moda, mas de como as representações para o vestir feminino, com produto e processo das apropriações, das intervenções e das significações sobre os corpos, ${ }^{3}$

1 JODELET, Denise (org.). As representações sociais. Rio de Janeiro: EDUERJ, 2001. p.16.

2 CRANE, Diana. A moda e seu papel social: classe, gênero e identidade das roupas. São Paulo, Senac, 2006. p.47.

3 As reflexões que conduzem a narrativa têm suporte nos conceitos de corpos, como produtos e produções culturais das roupas e da moda, conforme GOELLNER, Silvana V. A produção cultural do corpo. In: LOURO, Guacira L.; NECKEL, Jane Felipe; GOELLNER, Silvana V. (orgs.) Corpo, gênero e sexualidade. Um debate contemporâneo na educação. Rio Janeiro, Vozes, 2003, p. 2840; CASTILHO, Kathia. Moda e linguagem. São Paulo, Anhembi Morumbi, 2004. 
encontraram, nos cortes e nos volumes, os instrumentos para tratar da maternidade com as mulheres.

Nesse longo percurso, no século XV quando "o peito é destacado pelo decote", o ventre é "sublinhado por saquinhos proeminentes escondidos sob o vestido", 4 ou, "a abundância de tecido era presa por uma cinta sobre o seio", 5 os trajes criavam efeitos de gravidez, ao aumentarem a barriga com volumes concentrados na parte da frente das roupas.

Entre os séculos XV e XVIII, as linhas indumentárias com essas características arquitetônicas de amplitudes no ventre são renovadas. Permanências e mudanças nos "detalhes de forma, nas nuanças de amplidão", mediante acréscimos e ressignificações que são "torrentes de "pequenos nadas" e "pequenas diferenças que fazem toda a moda", 6 transformando as roupas em favoráveis aos usos pelas grávidas.

Naqueles séculos, o aumento do volume corporal na parte correspondente à barriga continua a ser utilizada. Complementos vestimentares que reforçavam os contornos de corpo grávido validavam a impressão. Um avental franzido sobre o vestido aumentava o efeito de gravidez ao colocar em destaque a barriga. No século XVII, os volumes dos seios são aumentados por meio de tecidos que, separados das saias, dividem o corpo entre o busto e a barriga com fitas e laços.

No século XVIII, o robe volante é uma síntese estética das manipulações dos volumes operacionalizada pela moda. Completamente redondo, o vestido assemelhava-se a um saco, em razão das pregas na frente e nas costas". Chamado de "vestido Watteau" ou "vestido com pregas Watteau" por ter sido objeto dos registros pictóricos de Antoine Watteau", tratava-se de estilo

4 LIPOVETSKY, Gilles. O império do efêmero. A moda e seu destino nas sociedades modernas. São Paulo: Cia das Letras, 1989, p. 29.

5 FOGG, Marnie. Moda: la storia completa. Bologna: Atlant, 2014, p. 47.

6 LIPOVETSKY, Gilles. O império do...”, 1989, p. 31.

7 FOGG, Marnie. Moda...., 2014, p. 57.

8 FERRARA, Laura. A moda em movimento: a obra de Antoine Watteau (1684-1721) e as origens modernas de um fenômeno. dObra[s]. v. 9, n. 20, 2016. p. 8-25. Disponível em: <https://dobras.emnuvens.com.br/dobras/article/view/474>. Acesso em: jun. 2017. 
indumentário que conferia certa dose de liberdade e conforto ao corpo.

Os estilos indumentários com cortes e volumes, além de possibilitarem abrigar a criança no ventre que crescia um pouco a cada mês, ajustavam-se às concepções e representações que marcariam a história do vestir durante a gravidez. Ou seja, as roupas amplas, ao favorecerem os seus usos pelas grávidas, faziam circular as concepções religiosas, científicas, políticas sobre/para o corpo feminino, beneficiando a assimilação daquele que era o novo papel social, o de mãe, junto com as transformações corporais da gravidez.

Por conseguinte, nos estilos indumentários dos séculos XV ao XVIII, as concepções religiosas sobre corpo e gravidez se tornam nítidas. Lembremos que a primeira representação de maternidade na história da procriação é a da virgem Maria, a qual ocorre como milagre divino, sem o ato sexual. Não nos esqueçamos, também, das representações de Maria como mãe, em que o filho, o menino Jesus, é o indivíduo cuja representação, junto à Maria, comanda as narrativas visuais na composição de imagens para a maternidade da virgem, configuradas sempre em tons claros e delicados. Não existem imagens da Virgem Maria grávida.

Ainda nas representações religiosas, a mácula do pecado e do ato sexual estaria presente nas demais mães do mundo, a exceção de Maria. Desta forma, para diminuir a "culpa" da luxuria do ato sexual, caberia à mulher ser uma boa mãe, ou seja, colocar a criança em primeiro lugar na sua vida, ser recatada, ser generosa, ser compreensiva e sofrer calada. Eis o ideal cristão de maternidade que deveria ser o norte das mulheres em geral. ${ }^{9}$ Nele, estão os conceitos e as representações que, historicamente, fundamentaram as noções de mãe e de maternidade para as construções simbólicas de gênero.

Concepção de feminilidade materna que transformava a criança no ventre em certificado social do pecado sexual que lhe deu origem. Assim, os vestidos que sublinhavam partes do corpo feminino com recortes, tecidos e usos de complementos que permitiam que, em meio aos volumes das saias, a futura criança pudesse ser escondida,

9 VÁSQUEZ, Giorgiane. Maternidade e Feminismo: notas sobre uma relação plural. Revista Trilhas da História. Três Lagoas, v.3, n. 6, p.167-181, jan-jun, 2014. 
materializavam, em roupas, as concepções religiosas dos silêncios e ocultamentos que deviam permear a procriação e a relação das mães com o corpo durante nove meses.

No século XIX, às linhas indumentárias que, em consonância com as representações religiosas, eram favoráveis aos usos pelas grávidas, juntam-se outras, desfavoráveis. No período, tornou-se comum a forma $\mathrm{X}$ para os vestidos, os quais comprimiam o corpo por meio dos espartilhos que estetizavam os papéis de esposa e mãe do casal burguês. ${ }^{10}$

A estética indumentária sempre reúne a moral e o consumo e os efeitos se entrelaçam. ${ }^{11}$ Nos espartilhos, como representantes da evolução da moda íntima e da revolução têxtil e higiênica do período, ${ }^{12}$ veiculavam-se os mecanismos para a difusão de representações que compatibilizavam o design das roupas ao modelo dominante de feminilidade, fabricado de acordo com a moral burguesa da mulher-mãe, vinculada ao universo doméstico dos cuidados da casa e da família e, para os homens, o espaço público, dos negócios, do trabalho.

Consumo de espartilhos e da moral burguesa que, ao instituir a cintura como dimensionadora de beleza e elegância do corpo feminino, mediante a sua valorização pelas roupas, desenvolveu estratégias para favorecer o uso pelas grávidas. Os corpetes com reguladores, que podiam ser distendidos à medida que a barriga crescia, prometiam sintonizar as grávidas com a moda. Na imprensa europeia, os corpetes com regulagens eram anunciados com indicações para as "jovens senhoras e esposas", uma referência às mulheres grávidas, considerando-se na definição a idade que, em geral, a gestação ocorria ${ }^{13}$.

10 MELlO E SOUZA, Gilda. O espírito das roupas: a moda no século XIX. São Paulo: Companhia das Letras, 1987. p.59.

11 ROCHE, Daniel. História das coisas banais. O nascimento do consumo do século XVII ao XIX. RJ: Rocco, 2000. p.261.

12 GELLACIC, Gisele Bischoff. Uma breve história daquilo que não se vê: os lingeries e as funções sociais femininas. In: FAZENDO GÊNERO 10, Desafios atuais dos feminismos. Anais... Florianópolis-SC, 16 a 20 de setembro de 2013.

13 POLI, Doretta Davanzo. Il Novecento, storie di moda. Le vesti dell' attesa. Modena: Zanfi Editori, 1988, p. 26. 
A relação entre beleza e função materna ganha novos contornos a partir dos anos 1920, porém, a barriga da grávida não era uma imagem valorizada. A mulher considerada "naquele estado devia primar pela discrição". Como resultado, "os conselheiros preferiam associar a beleza da maternidade ao período posterior ao nascimento do filho e não aos nove meses de espera.". ${ }^{14}$

Discrição que pode ser explicada pela permanência das influências religiosas e dos conhecimentos da ciência da mulher que vão redimensionar os conceitos de maternidade tendo em mira a criança, portanto, o desempenho do papel de mãe no cuidado do bebê. No século XIX, o parto, como momento que marcava o início da maternidade, ganha roupa especial: um vestido, descrito nos textos da obstetrícia de 1840 como "camisola que descia até o quadril e saia ampla aberta de lado, com laço ou apenas com bainhas dos lados". ${ }^{15}$ $\mathrm{O}$ uso da camisola pela parturiente possibilitava ao médico acompanhar o parto ao lado da gestante, com reserva e discrição, normas de conduta estabelecidas no tratamento das grávidas, limitando o contato físico durante os tratamentos e as intervenções.

No mesmo período, a valorização dos seios, parte do corpo feminino sobre os quais os discursos sobre amamentação proferidos pelos médicos do século XIX e XX vão incindir, é traduzida pela moda por meio do surgimento do sutiã, que se torna uma peça independente do espartilho e com características técnicas, sociais e políticas. Por volta de 1840 , os cadarços dos sutiãs são aprimorados e passam a desempenhar várias funções na vida íntima e social da mulher, entre as quais, a de desnudar-se ou vestir-se sem ajuda de outra pessoa, quer fosse uma doméstica, o marido ou o amante. ${ }^{16}$

Incluímos nessas funções sociais e íntimas dos cadarços ajustáveis a de possibilitar que a mulher acompanhasse as transformações corporais pelo aumento do volume dos seios durante e depois da gestação. Indiretamente, o sutiã contribuía para reforçar as representações simbólicas dos seios na amamentação e do papel das

14 SANT’ANNA, Denise Bernuzzi de. História da beleza no Brasil. SP: Contexto, 2014, p. 41.

15 Tradução nossa. No original, "camiciola che scende fino alle anche e larga gonna aperta di lato, con laccio o guaina aperto su fianchi”. POLI, Doreta Davanzo. Il novecento...1988, p. 31.

16 PRIORE, Mary Del. Histórias do cotidiano. SP: Contexto, 2001. 
mães nas relações com os recém-nascidos que, no período, é marcado por investimentos dos médicos, dos governos e das instituições filantrópicas para romper com as práticas que a alicerçavam, qual seja, o emprego das amas de leite. No compasso da transformação dos seios em alvos do interesse político-social, ${ }^{17}$ os sutiãs davam materialidade às referências sobre o aleitamento, assunto central nas orientações médicas das práticas de cuidados maternos até a contemporaneidade.

Nas roupas femininas, a maternidade foi e continua sendo comunicada de diversos modos, incutindo atitudes e maneiras de as mulheres lidarem com os aumentos corporais advindos da gravidez, mas também da gordura. Historicamente, vestimentas amplas e aquelas que podiam ser ampliadas com o uso de laços, fitas e cadarços sempre foram favoráveis aos usos das grávidas e de outros segmentos femininos cuja gordura corporal faz aumentar a barriga e eliminar a cintura, um valor social e cultural fabricado pela moda para o corpo das mulheres, sempre redimensionado desde o espartilho.

No século XX, a história da cintura narrada pelas roupas é reveladora de como os modelos de feminilidade, juventude e maternidade se cruzaram para tratar de corpo feminino, beleza e elegância. As roupas do costureiro Paul Poiret, no início do século, figuram como expressão das formas aerodinâmicas. "Leveza e velocidade eram valores caros aos jovens que descobriram o frisson das corridas de automóvel, a vertigem proporcionada pelos esportes naúticos e aéreos, além de frenéticos ritmos musicais."18 Nessa formulação teórica da estética, o uso de cintas é criticado, bem como o de roupas pesadas e volumosas. "Moda feita de superfícies lisas, avessa aos obstáculos e constrangimentos" $"$.

Em meados do século XX, a silhueta feminina do século XIX, com centro na cintura, é atualizada por Christian Dior. O new look era descrito da seguinte forma: "vendo-se de cima para baixo, a arquitetura feminina iniciava com uma saia elevada, convergindo para

17 YALOM, Marilyn. História do Seio. Coleção Teorema Série Especial, Lisboa: Ed. Teorema, 1998, p. 143.

18 SANT’ANNA, Denise Bernuzzi de. História da beleza....,2014, p. 54.

19 Idem. 
a cintura mínima, a sustentar seios ogivais". ${ }^{20}$ As influências do new look na moda feminina se dimensionam pela extensão internacional, como a primeira moda e vestimenta a "atingir populações dos cinco continentes, contribuindo para o surgimento de um vestuário internacional, que começara a se insinuar desde o surgimento da máquina de costura, no século XIX". ${ }^{21}$ Na perspectiva dos usos pelas mulheres, uma das explicações para a influência exercida pela roupa estava no apelo erótico das curvas proporcionadas pelo aumento de volume dos tecidos e das armações com dobras e franzidos que edificavam uma forma feminina, semelhante à ampulheta. ${ }^{22}$

$\mathrm{O}$ vestido new look, com suas linhas e volumes, sintonizava as mulheres com as noções de corpo ideal, magro, bem delineado por ginásticas e pelo uso de cremes, sem vestígios de gordura. Essa era a configuração estética disseminada pelas esferas da educação do corpo e da aparência, na Europa e no Brasil, pela moda, por meio do cinema, da televisão, das atrizes e de suas formas físicas oferecidas ao público por meio das revistas. Modernização das aparências que difundiam ideias de beleza em consonância às formas concebidas socialmente como perfeitas, na medida certa da equação dos volumes. $^{23}$

$\mathrm{Na}$ primeira metade dos anos 1960, as influências do new look de Dior ainda se faziam notar. Além dos vestidos, as saias eram ajustadas às cinturas ou delineavam os corpos com destaque naquela parte. $^{24}$ Do mesmo modo que a moda encontrou meios para incorporar a maternidade nas vestimentas nos séculos anteriores, na imprensa italiana, por exemplo, as mulheres são orientadas a usar

20 MEDEIROS FILHO, João Quintino. Moda e gênero: o vestuário sexualizado no new look de Christian Dior (anos 1950). Revista de Humanidades, v. 16, n. 37, p. 10-36, jul./dez. 2015, p. 13.

21 MEDEIROS FILHO, João Quintino. Moda e gênero..., 2015, p. 13.

22 MEDEIROS FILHO, João Quintino. Moda e gênero..., 2015, p. 13.

23 SANT'ANNA, Denise Bernuzzi. História da beleza..., 2014.

24 Concordamos com as intepretações de Mendes, Valerie; Haye, Amy e de Rainho de que os anos 1960 podem ser facilmente divididos em dois, a primeira metade ainda bastante tradicional e a segunda, onde a cultura jovem toma conta e o new look praticamente desaparece. Em nosso entendimento, em 1963, os trânsitos e os diálogos entre várias tendências e influências se fazem notar e a estética da cintura perdura como dimensionadora do corpo feminino em suas faces de elegância e beleza. De certa forma, as roupas com cintura e sem cintura instituem maneiras de a moda feminina pensar as corporalidades e as gerações. Ver: MENDES, Valerie; LA HAYE, Amy. A moda do século XX. São Paulo: Martins Fontes, 2003. RAINHO, Maria do Carmo Teixeira. Moda e revolução nos anos 1960. Rio de Janeiro: Contra Capa, Faperj, 2014. 
elásticos ou outras espécies de expansores, como a fita velcro, de maneira a adequar as saias ao corpo grávido. ${ }^{25}$

Delineava-se, por meio da cintura, uma maneira para falar de gravidez com as leitoras, na qual a barriga aparecia secundarizando as narrativas. No Brasil, a valorização da barriga da gestante pelo mercado da moda está diretamente relacionada às transformações sociais, culturais e políticas envolvendo as jovens e seus corpos.

Nesse aspecto, não parece aleatório que, na história das mulheres e da moda, a exposição do corpo de Leila Diniz grávida, em 1971, na praia de Ipanema, tenha se transformado em fato emblemático da valorização e da incorporação da barriga nas representações midiáticas, vetor de visibilidade e publicização do femômeno da gestação. Como escreveu Mirian Goldenberg, "com seu corpo grávido de biquíni na praia de Ipanema, em 1971, Leila é, até hoje, a melhor representante da revolução feminina ocorrida nas décadas de 1960 e 1970, quando as brasileiras libertaram seu corpo dos papéis tradicionais de mãe e esposa e inventaram novas formas de ser mulher." 26

Dos anos 1960 a 1971, entremeando os silêncios ou os modos de abordar a gravidez, o editorial de moda para Futura Mamãe, publicado pela Manequim, em 1963, constitui-se em evidência das transformações no tratamento de assuntos relativos ao corpo grávido.

\section{Manequim para mamães}

No Brasil, as concepções de que existem assuntos pertencentes às mulheres no que se refere às roupas e à necessidade

$25 \mathrm{Na}$ Enciclopédia Della Donna, periódico dedicado ao público feminino, nos editorais de moda pré-mamman, a palavra "incinta", que significa sem cintura, era empregada para definir a mulher grávida. Ver: ENCIPLOPEDIA DELLA DONNA. Grande enciclopedia di nozioni pratiche e di cultura generale per le donna.Fratelli Fabri Editori, v. 2, 1963.

26 GOLDENBERG, Mirian. Corpo, envelhecimento e felicidade na cultura brasileira.

Contemporânea, ed. 18, v. 9, n. 2, 2011, p. 77-85, p. 78 . Disponível em: 〈http://www.contemporanea.uerj.br/pdf/ed_18/contemporanea_n18_06_Mirian_Goldenberg.pdf〉. Acesso em: mar. 2017. 
de educá-las para desempenhar seus papéis de mãe e esposa orientaram as publicações da imprensa classificada como feminina, surgidas no mercado editorial do país desde o século XIX, com os primeiros exemplares de jornais ${ }^{27}$. A apresentação de modelos indumentários para os gêneros, dividida em diversas faixas etárias a fim de serem copiados, de moldes de roupas para serem reproduzidos, bem como séries de desenhos temáticos para serem aplicados sobre os panos, os quais estimulavam o bordado, foram recursos desenvolvidos por meio de ilustrações, gravuras e, posteriormente, as fotografias.

Para tratar de questões relativas aos corpos femininos na sua intimidade, como a menstruação e a gravidez, a imprensa desenvolveu, ao longo do século XX, estratégias para abordá-las, de modo que as atitudes de discrição e de recato, concebidas como ideais femininos, fossem incentivadas. Isso incluía tratar da moda na perspectiva das roupas e dos comportamentos. Com variáveis, essas práticas de comunicação estavam presentes em vários jornais e revistas e, a título de exemplo, podemos citar o Jornal das Moças $(1914-1965){ }^{28}$

A expansão das revistas direcionadas ao público feminino entre os anos 1950 e 1960 foi marcada pela atualização dessas estratégias comunicacionais. A revista Manequim, criada em 1959, é representativa de como os mecanismos comunicacionais entrecruzaram-se com a segmentação editorial para tratar de moda com as leitoras. A contribuição de Silvana Alcorso, esposa de Vitor Civita, nas edições da revista foi decisiva na definição de sua linha editorial: sintonizar as brasileiras com a moda internacional e nacional. No que tange ao mercado interno, almejava-se alavancar o consumo dos bens e produtos nacionais, tecidos e roupas prontas oferecidos pelo comércio. A divulgação de modelos e moldes que

27 LUCA, Tania Regina de. História dos, nos e por meio dos periódicos. In: PINSKY, Carla Bassanezi (Org.). Fontes históricas. São Paulo: Editora Contexto, 2005.

28 O Jornal das Moças era produzido no Rio de Janeiro. Durante o período de sua circulação, 1914 a 1965, a publicação de modelos e de moldes de roupas para serem costuradas e replicadas com as agulhas de tricô e crochê foi uma das características do periódico no seu relacionamento com as mulheres. 
podiam ser reproduzidos pelas leitoras se firmaria na história da revista como tendência editorial que a diferenciava das outras. ${ }^{29}$

O papel que a revista Manequim passa a desempenhar na viabilização do projeto de consumo da moda brasileira pode ser dimensionado quando se consideram alguns fatos: a realização da primeira Feira Industrial das Indústrias Têxteis (Fenit), organizada em São Paulo entre 1958 até os anos 1970; o uso dos fios sintéticos pela Rhodia; e, a necessidade de dinamizar a propaganda de maneira a que caísse no gosto das/os brasileiras/os. Esses aspectos exigiram o desenvolvimento de estratégias de comunicação que viabilizassem o consumo de tecidos e de roupas prontas, cuja produção vai se expandir por meio da ampliação do parque industrial e da rede comercial de lojas. ${ }^{30}$

As segmentações do mercado de consumo entre a moda de luxo e a "pronta para vestir" e de consumidores/as em categorias geracionais, classes sociais e gêneros, movimentam o mercado editorial, criando públicos e maneiras de abordar e propor roupas. Entre as segmentações, a do mercado de produção de modelos voltados para os/as jovens. A mudança proporcionava que eles e elas encontrassem nas lojas as vestimentas próprias às suas idades. Rompia-se, assim, com a relação histórica na qual moças e rapazes usavam as mesmas roupas que seus pais e mães. ${ }^{31}$

Entre as jovens e as senhoras, a gravidez e a preparação das mulheres para o desempenho do papel social de mãe. A edição da Manequim dedicada à Futura Mamãe, título do suplemento, é indicativa de como a fase que antecedia a transformação das mulheres em mães foi incorporada pela moda feminina, segmentando e fortalecendo o mercado de roupas para grávidas.

Futura Mamãe foi publicada em fevereiro de 1963 e teve tiragem de 66.400 exemplares, ao custo de CR\$1,50. Considerando o valor do salário mínimo de CR $\$ 21.000,00$, o custo representava 0,08

29 MIRA, Maria Celeste. O leitor e a banca de revistas: a segmentação da cultura no século XX. São Paulo: Olho d'água/Fapesp, 2001.

30 BONADIO, Maria Claudia. Moda e publicidade no Brasil nos anos 1960. São Paulo: InVersos, 2014.

31 ZIMMERMANN, Maíra. Jovem Guarda: moda, música e juventude. São Paulo: Estação das Letras e Cores, 2013. 
$\%$ daquele total. Esses números levam a pensar que o segmento de gestantes, com o qual a revista dialogava, era aquele formado por camadas médias e altas da população, com poder aquisitivo para investir na compra de roupas para vestir seus corpos, na provisoriedade de um tempo.

Neste fragmento, estão as pistas que contribuem com este pensar,

Futuras mamães, agora você pode vestir-se, com criações bem brasileiras! Tecidos, nossos modelos que você encontrará nas mais conhecidas casas de modas. No vestido, à extrema direita, a popeline adotou o "jabout" (Beija-flor, Rua São Bento, 352, SP). A seu lado, a cambraia estampada, com seu bôlso divertido, debruado de fustão branco (Sloper, SP e Rio). Muito bem-comportado, em algodão mescla vermelho e branco, o môdelo à esquerda é enfeitado com piquê branco (Jolie Maman, Rua Augusta, 1771, SP). Em shantung flamengo azul, vestido com duas pregas embutidas e dois bolsos altos (Mappin, São Paulo) ${ }^{32}$.

A parceria entre a editora Abril e os empresários do comércio de roupas distribui-se nas 109 páginas da edição. Do total de propostas indumentárias, configuradas em imagens em preto e branco, em dez delas as roupas são identificadas pelas lojas onde as leitoras podiam adquiri-las. Ganham destaque as empresas de São Paulo, algumas com indicação do endereço. Além do Mappin, que aparece em dois modelos, são destacadas as lojas Beija-Flor, na Rua São Bento, 352; a Jolie Maman, na Rua Augusta, 1771; a Modas Ilesta, na Rua 24 de Maio, 253; e a La Bella Mamma, Rua Amador Bueno, 29. Além dessas, constavam ainda a Sensação Modas e a Clipper, sem nota de endereço.

Nas páginas finais, com o título "endereços úteis para a futura mamãe", a lista de lojas nos estados e cidades completava-se. 
Além de São Paulo, mencionavam-se casas comerciais na cidade de Santos, Rio de Janeiro, Fortaleza, Minas Gerais (em Belo Horizonte e Juiz de Fora), João Pessoa, Curitiba, Londrina, Recife e Porto Alegre. $^{33}$

Ao dar visibilidade às lojas, a Manequim fornecia os modelos que, mesmo sem os moldes, se transformavam em fator de consumo para diversos segmentos sociais de grávidas, definidas a partir do poder aquisitivo. Para aquelas que podiam comprar a roupa pronta, as lojas; para aquelas sem condições de fazê-lo, os modelos que podiam ser reproduzidos por conta própria ou com a ajuda de uma costureira. Logo, o consumo de tecidos, parte da engrenagem do mercado da moda para fortalecer a produção têxtil e a distribuição pelas lojas, é evidenciado nos modelos.

Fazer ou comprar são verbos que ligavam as leitoras ao consumo de tecidos e de roupas, de acordo com os bolsos, mas também com as avaliações pessoais acerca da necessidade de produzir uma vestimenta apropriada à gravidez. Como afirma Lipovetsky, a moda concilia uma regra para o vestir e uma decisão pessoal, ditada pelo gosto, estilo e até mesmo pela necessidade. ${ }^{34}$

Os modelos oferecidos nas dez imagens, em preto e branco, selecionados para compor a edição, levam a refletir sobre como as propostas indumentárias dialogam com a moda jovem, de maneira a

33 Com base nas informações fornecidas por Manequim, é possível traçar um mapa das lojas que tinham entre seus itens de vendas, as roupas adequadas para as gestantes. Em São Paulo havia 16 lojas: A sensação, Beija-flor, Cisne, Clara Gross, Clipper, Estrela Modas, Flora \& Helena, Ilesta, Jolie Maman, Katarina, Laura, Leila, Marie Claire, Miranda, Plêiade, Sears Roebuck. Em Santos, 05 lojas: A feiticeira, Casa Etam, Casa Lemcke, Casa Moisés, Galeria Paulista de Modas. No Rio de Janeiro, 19 lojas: A Exposição Carioca, A moda Paris, Casa Anita, Casa Lucy Modas, Casa Hilda, Casa Amaral, Casa Masc, Del Rio Modas, Etam, Future Maman, La bambina Modas, Magazin Lucia, Mesbla, Modas Aladin, Rozano Trajes Femininos, Sears, Sezzete Pré-maman. Em Fortaleza, 07 lojas: Casa Helena de Troia, Casa Vênus de Milus, Dedal de Ouro, Exposição Gloria, Feira Paulista, Lojas Antenas, Magazine Sucesso. Em Belo Horizonte, 06 lojas: A Guanabara, A Sibéria, A vantajosa, O mundo colegial, A cinta moderna. Em Juiz de Fora, 03 lojas: A beira-mar, A conveniência, A Gatinha. Em João Pessoa, eram 03: Casa Carvalho de Armarinhos, City Modas, O nôvo continente. Em Curitiba, 04 lojas: A Modelar, Moda Etam, Modas Únicas, Modas Cinelândia. Em Londrina, 05: Armarinhos Paulista, Casa Modas Real, Casa Tôrres, Casa Fuganti, Modas Maria. Em Recife, 07: A primavera, Benjamim Tatchinick, Casa Mery Modas, Grizz Magazine, Francisca Soares de Souza, Kadô Boutique, Magazine Elegante. Em Porto Alegre, 09, Casa Arlindo, Casa Lyra, Casa Lu, Casa Schimitd, Casa Tschiedel, Loja Garça, Lojas Renner, Modas Etam, Modas Tabajara. Em Florianópolis, 05: A modelar modas, A Macedônia, Magazin Mademoiselle, Magazin Hoepeck, Modas Clipper.

34 LIPOVETSKY, Gilles. O império do...., 1989. 
fortalecer as representações do valor da maternidade para as moças, a estimular a aceitação das perdas das medidas da cintura, em decorrência do paulatino aumento da barriga e, finalmente, garantir a permanência da beleza e da elegância durante nove meses, conceitos basilares dos vínculos entre as pessoas, suas corporalidades e a moda.

\section{Roupas jovens para mamães}

Na década de 1960, observam-se mudanças significativas nas relações das jovens com o corpo e com o mundo. $\mathrm{O}$ acesso à educação e a maior profissionalização feminina, o surgimento da pílula anticoncepcional em 1962 e as reinvindicações feministas de direitos à sexualidade e à procriação, ganhavam voz. Todavia, o modelo dominante de feminino e de feminilidade era o da esposa e mãe. Casamento e maternidade permaneciam como "destino da mulher". Ser mãe (depois de tornar-se esposa, é claro!) conferia-lhe uma posição social de prestígio na sociedade, maior que qualquer outra 'carreira'. Não desempenhar o papel materno seria algo como "trair a essência feminina." "3

Como pondera Pinsky ${ }^{36}$ na análise da história das mulheres, "grosso modo, podemos identificar dois momentos" nos modelos de feminidade, um deles, que se consolida no início do século $\mathrm{XX}$, denominado pela autora como "rígido" e, outro, de meados dos anos 1960 aos dias de hoje, concebido como de "maior fluidez", ambos marcados por questionamentos e pela emergência de novos pilares de referências para pensar a vida e os relacionamentos, ampliando, assim, as visões de mundo.

35 SCOTT, Ana Silvia. O caleidoscópio dos arranjos familiares. In: PINSKY, Carla B.; PEDRO, Joana Maria (Org.). Nova História das mulheres no Brasil. SP: Editora Contexto, 2012, p. 15- 42 , p. 24.

36 PINSKY, Carla Bassanezi. Imagens e representações. A era dos modelos flexíveis. In: __ _ PEDRO, Joana Maria. Nova História das mulheres no Brasil. SP: Editora Contexto, 2012, p. 513- 544, p. 520. 
Todavia, em meio a tantas mudanças, o modelo dominante de feminilidade era o casamento e a maternidade, o qual era endossado pela Igreja Católica, que reafirmava os princípios de feminino e maternidade ao defender que o exercício da sexualidade residia no casamento, portanto, na conjugalidade, e que a procriação era o seu objetivo. São para esses aspectos que a Carta Encíclica de 1968, redigida durante os embates entre as mudanças sociais e culturais, decorrentes principalmente dos métodos contraceptivos, que o documento de Papa Paulo VI, a Humanae Vitae (Sobre a Regulação da Natalidade), apontam ao afirmar que: "O matrimônio e o amor conjugal estão por si mesmos ordenados para a procriação e educação dos filhos. Sem dúvida, os filhos são o dom mais excelente do matrimônio e contribuem grandemente para o bem dos pais." ${ }^{, 37}$

"A perspectiva de maior controle dos processos relativos à reprodução humana, conjuntamente com o discurso da contracultura, que preconizava a libertação sexual, produziu efeitos sobre as práticas afetivas e sexuais das jovens." ${ }^{38}$ Novas concepções de corpos e de aparências, de maior liberdade para a vivência e a expressão da sexualidade são fenômenos assimilados e difundidos nas roupas direcionadas aos jovens.

Rebeldia e contestação que são simbolizadas pela minissaia, em 1963, criada por Mary Quant e cuja origem é controversa. ${ }^{39}$ A liberdade e o movimento são representados pela evidenciação das pernas. A cultura do corpo difundida pelas revistas incorpora a juventude como valor social para difundir práticas de cuidados corporais e de embelezamentos. Corpos magros e delineados, com cintura fina, tratados por meio de exercícios e dietas e pelo uso de produtos cosméticos que ajudam a melhorar a aparência da pele e dos cabelos, são representações que atingem as mulheres em geral. Cuidese é a palavra de ordem que vincula as mulheres ao consumo e às

37 PAUlO VI. Carta Encíclica Humanae Vitae, 1968. Disponível em: <http://w2.vatican.va/content/paul-vi/pt/encyclicals/documents/hf_p-vi_enc_25071968_humanaevitae.html>. Acesso em: 07 abr. 2014.

38 AREND, Silvia Fávero. Trabalho, escola e lazer. In: PINSKY, Carla Bassanezi; PEDRO, Joana Maria (Org.). Nova história das mulheres. São Paulo: Contexto, 2012, p. 65-83, p. 78.

39 ANDRADE, Mayra Z. A moda invade as ruas: consumo jovem nos anos 1960. D'Obras, v. 3, n. 7, p. 105-113, 2009. 
evidenciações das conquistas obtidas, ${ }^{40}$ por meio do uso de roupas que destacam as partes corporais para as quais são conferidas as representações da beleza, da feminilidade e da sensualidade, caso das pernas mostradas pela minissaia.

Na contramão do new look de Dior, está o vestido trapézio de Yves Saint Laurent, com linhas que se abriam ao corpo feminino a partir dos ombros. Sobre Saint Laurent, "nos anos 1960, sob a máscara da timidez, já se pode ver nesse rapaz o monstro sagrado no qual ele se transformaria. Quatro decênios mais tarde, Yves Saint Laurent não perdeu nada do seu mistério ou do seu magnetismo que, majestaticamente, exerce sobre o mundo da moda ${ }^{41}$ " para finalizar, "a sigla YSL adapta-se a todas as circunstâncias. A todas as categorias de clientes". ${ }^{42}$

A abrangência de destinatárias para uma linha de indumentária pode ser explicada pelo fato de que carreava e emblematizava vários símbolos de juventude, notadamente, deixar o corpo livre de destaques corporais da cintura e busto, como fazia a linha Dior. Por essa razão, podia desempenhar várias funções táticas nas relações das mulheres com as medidas e as aparências prescritas pela cultura estética da beleza feminina. A modelagem atendia aos princípios e às necessidades de ocultamento das formas físicas daquelas mulheres que, por alguma razão, fugiam ou não conseguiam atender aos padrões estéticos do "corpo violão" ou que vivenciavam o aumento das medidas por causa da gravidez. Acrescenta-se ao aspecto, o fato de diluir a segmentação etária ao vestir tanto a mãe quanto a filha.

Enfim, era um vestido cuja modelagem permitia várias apropriações e aproveitamentos, com a possibilidade de transformarse em objeto de múltiplas inspirações e de significações para o vestir feminino. A compreensão das potencialidades da linha trapézio como produto da alta costura e de sua disseminação está na reflexão de Lipovetsky ${ }^{43}$, de que a moda moderna articulou duas indústrias, a alta

40 SANT'ANNA, Denise Bernuzzi de. História da beleza ...., 2014.

41 BAUDOT, François. Moda do Século. Trad. Maria Thereza de Rezende Costa. $3^{\text {a }}$ ed. revista. São Paulo, Cosac Naify, 2002, p. 182.

42 Idem.

43 LIPOVETSKY, Gilles. “O império.....1989. 
costura e a confecção industrial. De um lado, a criação de luxo e sob medida e, de outro, a produção de massa, em série e barata, imitando - de perto ou de longe - os modelos e as grifes de prestígio da altacostura, fundamentando o binômio da criação de modelos originais e reprodução industrial.

No Brasil dos anos 1963, essas potencialidades são exploradas pelo sistema de roupas prontas para vestir. A transformação da linha trapézio em propostas indumentárias adequadas para as futuras mamães deixou rastros na Manequim. Na apresentação, as leitoras liam: "Veja como assenta bem às futuras mamães a linha trapézio: em algodão grosso, laranja ou amarelo limão, pespontado no decote (redondo), nas mangas e na barra do blusão.",44

A roupa em questão se tratava de um conjunto de saia e blusa em estilo trapézio. Na mesma página, com o título "Para futura mamãe, com carinho!", era composto por dois modelos de vestidos: o primeiro, como o conjunto, inspirado na linha Saint Laurent e, para o segundo, informava-se: "Chá às cinco horas? Com muito prazer!! Aproveite a ocasião para pôr êste modelo em amorela ou sêda estampada sôbre fundo branco, com um franzido saindo da cintura, rematada por uma pala". ${ }^{45}$

No ritmo "incessante e frenético das novidades", as roupas direcionadas para as grávidas são marcadas pela atualização de práticas de vestir corpos em gestação. No conjunto de saia e blusa, havia, debaixo do pano, escondido por entre os tecidos, a criança. A saia, marcando o quadril, deixava implícito algum tipo de corte ou complemento que ajustava a roupa à barriga. $\mathrm{O}$ vestido, com a cintura marcada que se abria para a saia franzida, ressignificava a versão indumentária que separava e destacava os seios e a barriga, por meio de cortes, volumes e detalhes de faixas para marcar as distinções entre as partes do vestuário.

Aspecto que merece atenção é a ausência da barriga como traço marcante nos corpos das modelos. Ao olhar algumas roupas, não é possível dizer que a mulher está grávida e, quando há algum 
destaque, o aumento é sutil. É provável que algumas não estivessem grávidas ou que a gestação estivesse em seus primórdios. No aspecto corporal, as modelos eram jovens. Considerando que o ciclo fértil das mulheres ocorre, em geral, entre os 15 e 45 anos, as imagens das grávidas que a revista veiculava parecem dirigir-se às moças, preparando-as para o primeiro filho, para o desempenho da função materna.

Pode-se dizer que, se o modelo de feminilidade sofria reveses no início dos anos 1960, impulsionada pela cultura da juventude que proclamava liberdade de viver a vida sob outros princípios ideológicos de corpo e sexualidade, as propostas indumentárias para as grávidas se constituíam em incentivo para o casamento e a gravidez. Elas proporcionavam que as jovens vivenciassem a gravidez sem abdicar dos valores sociais e culturais de beleza e elegância, de terem roupas apropriadas durante o período da espera da chegada do bebê.

Além dos vestidos, o estilo jovem de ser mãe é construído por meio das calças compridas. Com o título "Calças compridas? Por que não?", argumentava-se:

Não há motivo para abandonar uma indumentária tão cômoda como as calças compridas sob pretexto de que 'vai ficar horrivel, com essas curvas temporárias'. Com o charme de um dêstes blusões, você continuará tão feminina como sempre. O melhor é escolhê-los bem soltos e compridos, para se harmonizarem com as calças compridas, de pernas bem afuniladas para não tornar o conjunto 'pesadão'. Compre dois pares de calças, um escuro e outro claro, em tergal, popeline, helanca ou gabardine e combine-as com qualquer dêstas batas: da esquerda para a direita, cetim de algodão com mangas três quartos e gravata, com estampado bem vivo, mais flôres estampadas, com fundo branco, gola esporte $e$ 
uma fila de botões e, por fim, em algodão, uma camisa branca, de gola branca e palinha. ${ }^{46}$

Gravidez como momento de "curvas temporárias" que permitia que estilos indumentários do período anterior à gestação pudessem ser usados com adequações ao corpo modificado. Nesse fragmento, bem como em outros, a preocupação com a estética que fundamenta as narrativas fornece as pistas de que a beleza e a elegância, quando alocadas para a gestação, exploram os medos e os receios femininos de perder a forma física. Se a gordura, estrias e celulites eram males a serem combatidos pelas mulheres, ficar grávida significava o aumento de peso e das possibilidades de ficar feia.

Esses vestígios estavam nos títulos que se dirigiam às grávidas com os dizeres "um pouco... 'REDONDINHA', mas muito ELEGANTE", que por meio de letras garrafais associavam o aumento de peso e a possibilidade de permanecer elegante, e nas orientações de dietas e ginásticas. Controlar o peso e fazer ginástica eram as orientações para as futuras mamães: "quer você faça ou não um regime agora, é importante observar uma dieta durante a gravidez. Para bem de sua saúde e a do bebê, siga fielmente as regras da boa nutrição". Leite, frutas, cereais, legumes, carnes deviam ser consumidos diariamente com o alerta: "mesmo que você começar a engordar muito rapidamente, não pode dispensá-los" ${ }^{\text {"47 }}$. As ginásticas eram aconselhadas para:

[...] preparar a jovem mãe para o trabalho do parto e a prevenir distúrbios que poderiam ocorrer depois. Tem um objetivo puramente higiênico, como o de treinar os 
músculos da gestante, de tornar os tecidos tônicos $e$ elásticos e de combater a gordura ${ }^{48}$

A futura mamãe devia se cuidar por duas razões: para beneficiar o bebê e não ficar feia aos olhos do marido. Não nos esqueçamos que no período, cabia à mulher a manutenção do casamento. Tornar-se mãe completaria a felicidade conjugal. Portanto, cabia à mulher ser esposa e mãe e saber administrar ambos os setores, cuidando do marido e dos filhos. ${ }^{49}$

As lingeries podiam cumprir ambas as funções, ao tornar a grávida "Mais feminina ainda!". Sutiens, calcinhas e cintas deviam dar o "sustento de que o seu corpo precisa com o aumento de peso". "Guarde a cinta de todos os dias assim que notar que seu ventre começa a aumentar e compre uma especial" e a aconselhada era "a cinta helanca, com a parte de baixo elástica para apertar bem a barriga". Sutiãs que dessem sustentação aos seios, com aberturas que facilitassem a amamentação. Camisolas e peignoirs com cortes amplos que podiam ser usados durante e depois da gravidez são indicados. Um modelo de camisola, ganha a descrição: "De costas, você parecerá magrinha, com esta camisola cujo volume está na frente."

Como considerações finais podemos afirmar que assimilar e garantir que as grávidas pudessem ter roupas apropriadas ao período da gravidez foi o propósito da criação da edição especial da Manequim para a futura mamãe. Nas apropriações das roupas e em suas ressignificações para o corpo grávido evidenciam-se um conjunto de estratégias que contribuíam para movimentar o consumo de vestuário e de ideias sobre maternidade, prescrevendo maneiras de lidar com as transformações geradas pelo crescimento da criança e da barriga, como estética visual declaratória da gravidez e dos processos da maternidade em curso. Para tal, a promoção de tecidos brasileiros, como o algodão, se misturam com as sedas e as helancas na criação

48 MANEQUIM, Edição especial, n.44b, 1963, p. 44.

49 PRIORE, Mary Del. História do amor no Brasil. São Paulo: Contexto, 2005.

50 MANEQUIM, Edição especial, n.44b, 1963, p. 42. 
de modelos pensados a partir do Brasil, mas influenciados pela moda internacional. A cultura da beleza e do corpo produzia referências sobre como lidar com a barriga e com a gordura, como manter-se jovem, bela e elegante num momento de profundas transformações físicas, emocionais e psicológicas que marcam a geração e o nascimento de uma criança.

Condensando as representações, não menos importante é a ideia de amor materno, em que vestir-se significava acompanhar e desenvolver laços de afeto. Nesse contexto, perder a cintura e aumentar a barriga devia ser concebido como ato de amor, de abdicação de si, no caso das formas corporais, para dar forma a uma criança. Em suma, nas representações da e para a grávida, as roupas e a moda vestiram corpos, aproveitando o ato de gerar para fixar pontos de apoio para reforçar papéis, para incutir medos e esperanças, para tratar de beleza e elegância.

RECEBIDO EM: 01/03/2017 APROVADO EM: 10/07/2017 